Dr: $3^{\gamma}$

\title{
Preliminary Fission Product Energy Release Measurements for Thermal Neutron Fission of ${ }^{235} \mathrm{U}$
}

\author{
J. K. Dickens \\ T. A. Love \\ J. W. McConnell \\ J. F. Emery \\ R. W. Peelle
}




\section{DISCLAIMER}

This report was prepared as an account of work sponsored by an agency of the United States Government. Neither the United States Government nor any agency Thereof, nor any of their employees, makes any warranty, express or implied, or assumes any legal liability or responsibility for the accuracy, completeness, or usefulness of any information, apparatus, product, or process disclosed, or represents that its use would not infringe privately owned rights. Reference herein to any specific commercial product, process, or service by trade name, trademark, manufacturer, or otherwise does not necessarily constitute or imply its endorsement, recommendation, or favoring by the United States Government or any agency thereof. The views and opinions of authors expressed herein do not necessarily state or reflect those of the United States Government or any agency thereof. 


\section{DISCLAIMER}

Portions of this document may be illegible in electronic image products. Images are produced from the best available original document. 
Printed in the United States of America: Available trom National Technical Information Service

U.S. Department of Commerce

5285 Port Royal Road, Springfield, Virginia 22161

Price: Printed Copy \$4.00; Microfiche $\$ 2.25$

This report was prepared as an account of work sponsored by the United States Government. Neither the United States nor the Energy Research and Development Administration, nor any of their employees, nor any of their contractors, subcontractors, or their employees, makes any warranty, express or implied, or assumes any legal liability or responsibility for the accuracy, completeness or usefulness of any information, apparatus, product or process disclosed, or represents that its use would not infringe privately owned rights. 
Contract No. W-7405-eng-26

Neutron Physics Division

\section{PRELIMINARY FISSION PRODUCT ENERGY RELEASE MEASUREMENTS \\ FOR THERMAL NEUTRON FISSION OF ${ }^{235} \mathrm{U}$}

J. K. Dickens, T. A. Love, J. W. McConnell

J. F. Emery*, and R. W. Peelle

$$
\begin{gathered}
\text { Work performed by } \\
\text { Union Carbide Corporation } \\
\text { for }
\end{gathered}
$$

U. S, NUCLEAR REGULATORY COMMISSION under

Interagency Agreements 40-551-75 and 40-552-75

*Analyt1cal Chemistry Division

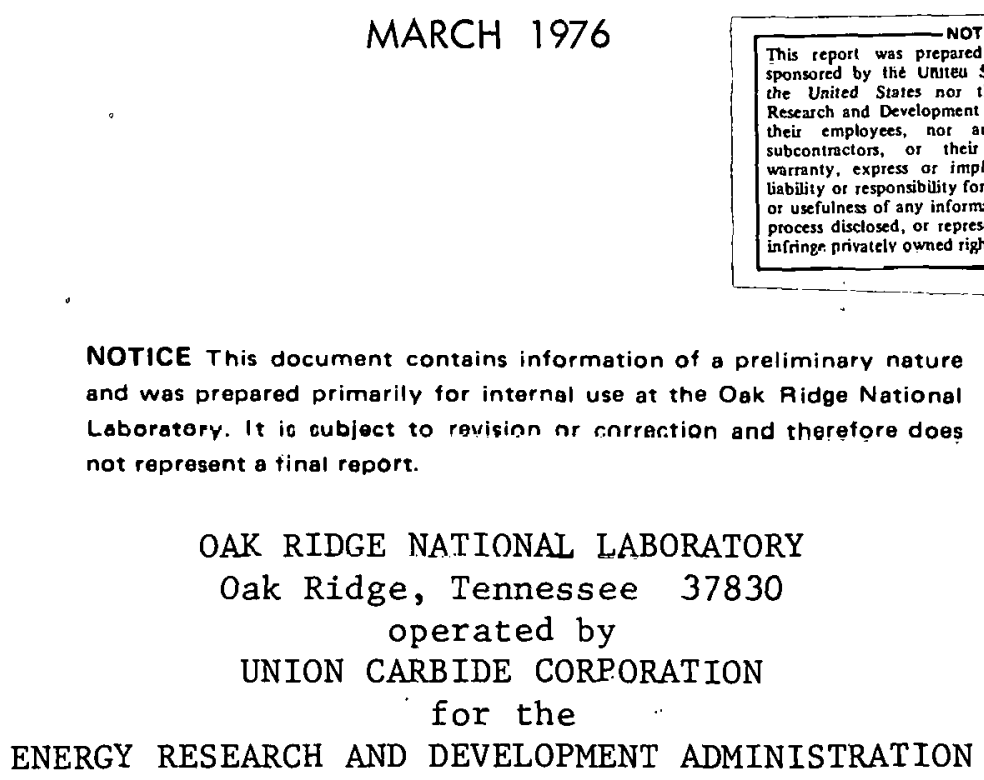




\section{THIS PAGE}

\section{WAS INTENTIONALLY LEFT BLANK}




\section{CONTENTS}

$\underline{\text { Page }}$

Abstract ........................ . . . 1

Introduction . . . . . . . . . . . . . . . . 2

Experimental Method . . . . . . . . . . . . . 3

Experimental Problem-Area Results . . . . . . . . . . . 6

Interim Gamma-Ray Energy Release Results . . . . . . . . . 8

Interim Beta-Ray Energy Release Results . . . . . . . . . 11

Acknowledgments . . . . . . . . . . . . . . 27

Appendix. Brief Resume of Computer Codes . . . . . . . . 28

References ..................... 33 
Abstract

An experimental system to measure time-dependent spectra of beta and gamma rays from fission-product production by thermal neutron fission of ${ }^{235} \mathrm{U}$ is described, and for each component (beta and gamma) the system has been tested with a pilot data-accumulation run. Data reduction techniques are described and test results given. Gamma-ray spectra are compared with calculations using ENDF/B-IV data files. Both beta- and gamma-ray spectra were integrated to give total yields and total energy-release results for times after fission between 3 and $14400 \mathrm{sec}$. These preliminary integral data are compared with previous measurements and with integral calculations using ENDF/B-IV data files. 


\section{INTRODUCTION}

In the event of a hypothetical loss-of-coolant-accident (LOCA) in a reactor the fissioning process would cease, and the major source of heat would be due to beta and gamma rays from the decay of the accumulated fission products. Other sources of heat, for example, activated structural nuclides and heavy actinides, depending on the details of the fuel rod fabrication, would contrlbute a few per cont. ${ }^{1}$ In 197.3 an evaluation of then existing data was reported by Perry, Maienschein and Vondy; ${ }^{2}$ they concluded that discrepancies among (and uncertainties assigned to) various data sets were such that a conservative (10) uncertainty assigned to a value of the rate of energy release after a time $\underline{t}$ following shutdown would be about $15 \%$. The implicit recommendation was that the overall uncertainty could and ought to be reduced.

The decay heat function can be obtained by two complementary methods. The first is based on integral measurements of the total beta and gamma power released; the second consists of cumulating the individual energies released by each and every one of the fission products. The second method, a large calculational problem, has the merit that once the method r.an satisfactorily reproduce integral measurements, it could be applied to more complex situations in a reactor, taking into account, for example, reactor power variations or the evolution of flesturable iantopec as a function of reactor operation. There are, at present, at least five active calculational efforts. ${ }^{3-7}$ A data base is required for all fission products which includes rates-of-production and energies and branching ratios of the decay products. Compilations of such data exist; ${ }^{8-12}$ however, especially for short-lived fission products, the data are incomplete. 
As a consequence, the need for additional information, particularly for $t$ less than $10^{3}$ seconds, prompted several new measurements. There are four currently under way in the United States: (1) a calorimetric measurement at Los Alamos Scientific Laboratory, ${ }^{13}$ (2) a second calorimetric measurement at the University of California, Berkeley, ${ }^{14}$ (3) a total-absorption measurement at Intelcom Radiation Technology, San Diego, 15 and (4) the present measurements at ORNL, consisting of separate differential energy measurements as a function of $\underline{t}$ for each component. The first three experiments mentioned will provide integral energy-release data for different irradiation and cooling times. The present experiment will provide, in addition, spectral distributions for computing high-energy gamma-ray leakage required by the other experiments. Furthermore, the spectral distributions will provide a more stringent test of the validity of the "microscopic" calculational approach.

\section{EXPERIMENTAL METHOD}

The basic concepts of this experiment have been presented in detail in a pievious memorandum, ${ }^{10}$ and many details of the fabrication and testing of equipment have appeared in quarter1y reports. ${ }^{17-20}$ The important design feasures are: (a) the uranium samples are small, nominally 1 , 5; or $10 \mu \mathrm{gm}$ enriched to $93.5 \%$ in the ${ }^{235} \mathrm{U}$ isotope; (b) the irradiation times are short, 2.4 and $100 \mathrm{sec}$ having been studied to date; (c) energy release is determined separately for betas and gammas using scintillation detectors and recording pulse-height information for individual events and then obtaining the energy-release data inferred from the resulting pulse-height spectra; and (d) the number of fissions, $n_{f} \sim 10^{8}$ per sample, is determined by measuring the yield of the $140.5-\mathrm{keV}$ gamma ray due to 99 Mo decay. 
In the first phase of the experiment, detectors were designed, fabricated, and subjected to bench tests. Electronics were purchased when available commercially; designed and fabricated locally when not. Methods for sample preparation and sample movements to and from irradiation positions were based upon an existing system, ${ }^{21}$ subsequently improved to allow automatic controls. Finally, a data-accumulation system was designed and implemented making use of an existing PDP-15 computer. All of the separate components were tested, and then transferred to the site of the experiment at the Oak Ridge Research Keactor. An overview of the experimental system is shown schematically in Fig. 1. The experiment calls for measurements of both beta and gamma radiation, and Fig. 1 shows the positions of both detectors. However, only one can be used at a time. A different sample holder is needed for each detector; in addition, although the same set of electronics is used, the analog settings are different for each detector.

Following the irradiation and measurements the samples are cooled for 45 to 80 hours and are then counted for the characteristic $140.5-\mathrm{keV}$ gamma ray of ${ }^{99}$ Mo decay using the $\mathrm{Ge}(\mathrm{Li})$ photon detector and Llie rulse Height Analyzer shown in Fig. 1.

The first data-taking runs were undertaken with the goal of uncovering the important problem arcas. For each component, gamma and beta, the first data-taking runs were scheduled as pilot runs, with a complete study of all aspects of the experiment from sample preparation through the final integrated energy release data. Major differences in planning between the pilot run and a full-scale run were the number of samples and the number of redundant overall system checks. 
ORNL-OWG $75-9473 R$

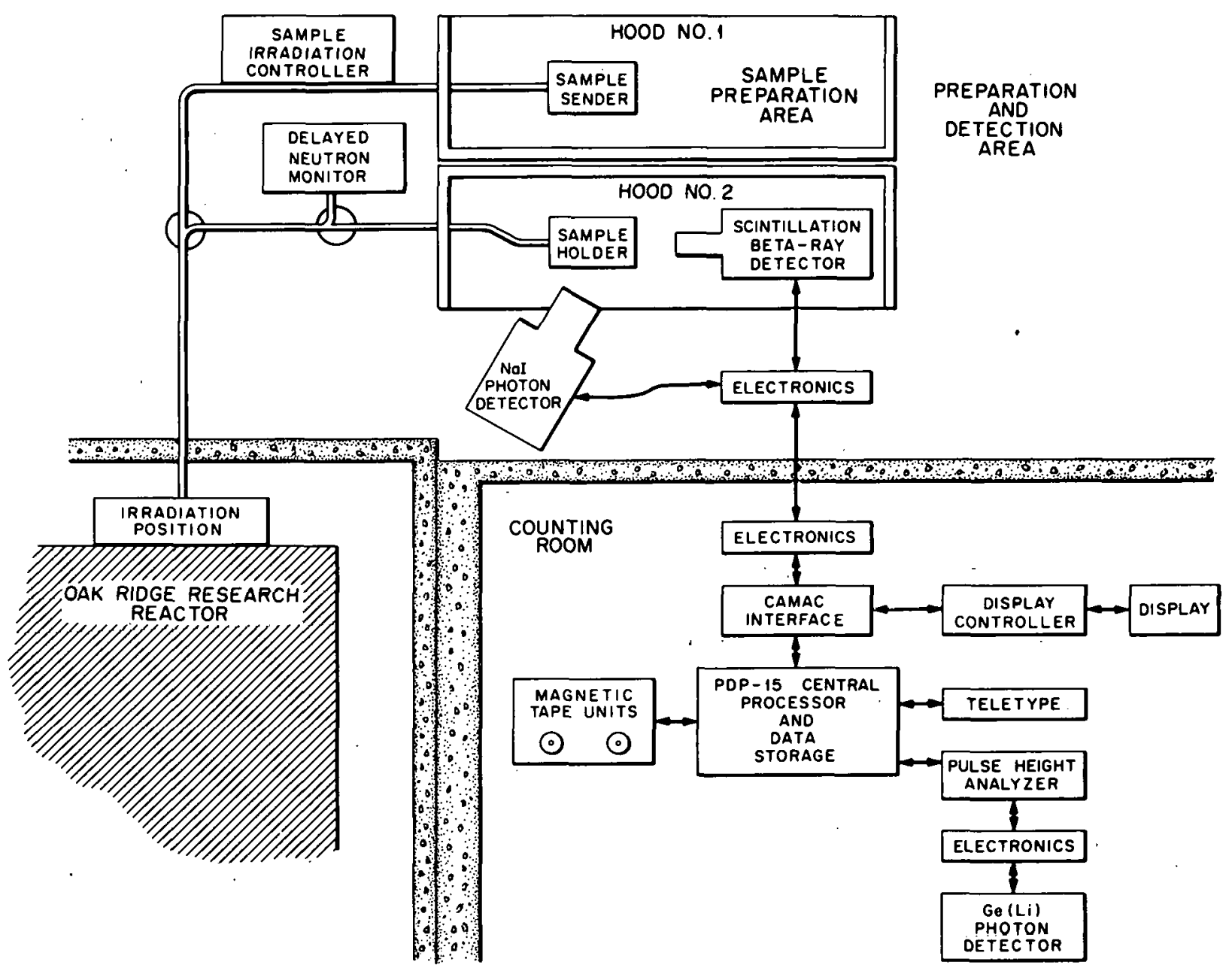

Fig. 1. Schematic representation of experimental arrangement for fission-product decay-heat measurement's. Samples of ${ }^{235} \mathrm{U}$ (or ${ }^{239} \mathrm{Pu}$ ) are placed in a rabbit and put in the Sample Sender. The Central Processor controls the movement of the rabbit to and from the Irradiation Position, then to the Sample Holder. After a specified cooling time, elther photons or beta rays are counted, and the data are stored in the Central Processor. At the completion of data accumulation the data are stored on magnetic tape for off-line reduction. 
Even for the pilot runs a tremendous volume of raw data was generated. Several dozen fission samples were run for each component, with additional samples for backgrounds and non-fissile measurements; and, as each sample had up to 16,384 channels of data, approximately a miliion numbers comprised the raw data for each component. Eight computer routines were written and/or made operational in order to acquire, save and transfer, and reduce the data. Brief descriptions of these routines are given in the Appendix to this report.

The energy-release data resulting from these pilot runs should be Indicative of data expected from the final runs. Improvements in the overall experimental system are expected to increase considerably the accuracy of final energy-release data. These interim results are reported at this time primarily to provide a lead time for preparation by other related programs which will use the final results. It should be stresscd that the present data will be superceded in the near future, and their use should be confined to unpublished work.

\section{EXPERIMENTAL PROBLEM-AREA RESULTS}

$\Lambda$ complete discussion of the gamma-ray data accumulation has been repnrted. 22 Likely the major source of uncertainty in these data is in the determination of $n_{f}$, the numbcr of fissions, which will he discussed below. Of the remaining possible sources of error, the response matrix ined to unfold the data needs to be more thoroughly tested with several well-calibrated multi-gamma sources. In addition, the possibility of any significant spectrometer sensitivity to delayed neutrons needs to be investigated. 
The beta-ray data accumulation experiment has also been reported. ${ }^{23}$ For these data, in contrast to the gamma-ray data, there are still several very difficult problems. The thickness of material between sample and detector must be minimized, but still be thick enough to stop energetic fission fragments and sturdy enough to withstand the mechanical shocks associated with transport to and from the reactor. For the pilot run this thickness was $\sim 55 \mathrm{mg} / \mathrm{cm}^{2}$, about ten times thicker than the desired minimum. To date, however, a satisfactory thinner sample holder has not been proven. The final thickness obtained will determine also the details of the final response matrix. Additional experimental data are needed to test this response matrix, since, unlike the gamma-ray response matrix, the beta-ray response matrix depends almost entirely on calculation. Another major unknown is the possible loss of gaseous fission products by diffusion through the plastic sample holders. Essentially nothing is known about the rates of diffusion of $\mathrm{Kr}$ and $\mathrm{Xe}$ through polyethylene. These will need to be measured to a precision consistent with importance to this program. Diffusion of $\mathrm{I}$ and $\mathrm{Br}$ may also need to be measured; tlie flrst tèsts of this problem, however, indicated that for $55 \mathrm{mg} / \mathrm{cm}^{2}$ thick sample holders there was no appreciable loss isotopes of I after 48 hours.

At present the determination of $n_{f}$, the number of fissions in the sample is determined by two methods, (a) by measuring the 140.5-keV transition in ${ }^{99}$ Mo some 40 to 80 hours after irradiation using the Ge(Li) system in Fig. 1, and (b) by measuring the neutron flux using a gold foil and computing $n_{f}$ from the known ${ }^{235} U$ sample mass and $\sigma(n, f)$. The overall uncertainty is $\sim 5 \%$. To reduce the overall uncertainty to $2 \%$, however, 
a better knowledge of the decay of ${ }^{9}{ }^{9} \mathrm{Mo}-{ }^{99} \mathrm{TC} *$ may be required. In addition, other fission product gamma rays may be used. For example, ${ }^{132} \mathrm{Te}$ has a strong $228 \mathrm{-keV}$ gamma ray; if this were to be used, a better determination of the branching ratio $^{24}$ would be required.

The major requirement for the thermal-neutron flux determination is to measure it at regular intervals throughout the experiment. A series of well-calibrated gold foils will be required. Possibly an Al foil will be used to supplement the gold foil measurements, since the half-life is conveniently short, so the same foil can be reused. In addition to the thermal-flux measurements, the effect of epi-thermal neutron fission must also be investigated.

\section{INTERIM GAMMA-RAY ENERGY RELEASE RESULTS}

The yield and energy-release per fission results are collected in Table 1, taken from Kef. 22. There are several waye of preparing these data for comparison with other data and calculations; the one chosen is to compare $\underline{t} x \mathrm{f}(\underline{t})$ as is done in Perry, Maienschein, and Vondy. ${ }^{2}$ Here $f(t)$ is defined as the energy release rate a time $t$ after a fission. To shtain the energy-release data in Table $1, f(t)$ is integrated twice:

$$
Y\left(T, L, t_{\text {count }}\right)=\frac{1}{T} \int_{t}^{t+t_{\text {coun } t}} d t^{\prime} \int_{t}^{t^{\prime}+T} d t^{\prime \prime} f\left(t^{\prime \prime}\right) \text {, }
$$

where $\mathrm{T}$ is the irradiation period. As may be noted at a glance from Fig. 2, the function $\underline{L} \times f(t)$ staye within a factor of two, or so, for $\underline{t}$ between 1 and $10^{4} \mathrm{sec}$. Perusal of Fig. 2, however, shows discrepancies among the data sets ${ }^{2-27}$ of amounts discussed in Perry, Maienschein, and Vondy. ${ }^{2}$ (In Fig. 2 small corrections were applied to the present interim 
Table 1. Photon Yields and Energy Release From Fission Products Created by Thermal-Neutron Fission of ${ }^{235} \mathrm{U}$

\begin{tabular}{|c|c|c|c|c|c|}
\hline \multirow{2}{*}{$\begin{array}{l}\text { Irradiation } \\
\text { Time } \\
\text { (sec) }\end{array}$} & \multirow{2}{*}{$\begin{array}{l}\text { Waiting } \\
\text { Time (a) } \\
\text { (sec) }\end{array}$} & \multirow{2}{*}{$\begin{array}{l}\text { Counting } \\
\text { Time } \\
\text { (sec) }\end{array}$} & \multicolumn{2}{|c|}{$\mathrm{E}_{Y} \geq 0.05 \mathrm{MeV}$} & $0.025 \leq \mathrm{E}_{Y} \leq 0.05 \mathrm{MeV}$ \\
\hline & & & $\begin{array}{c}\text { Yield } \\
\text { (photons/fission) }\end{array}$ & $\begin{array}{l}\text { Energy Release } \\
\text { (MeV/fission) }\end{array}$ & $\begin{array}{c}\text { Yield } \\
\text { (photons/fission) }\end{array}$ \\
\hline 2.4 & 3 & 2 & $0.232 \pm 0.027$ & $0.219 \pm 0.026$ & $0.0134 \pm 0.0021$ \\
\hline 2.4 & 5 & 2 & $0.175 \pm 0.014$ & $0.164 \pm 0.013$ & $0.0116 \pm 0.0015$ \\
\hline 2.4 & 7 & 2 & $0.140 \pm 0.012$ & $0.133 \pm 0.011$ & $0.0094 \pm 0.0012$ \\
\hline 2.4 & 9 & 5 & $0.259 \pm 0.024$ & $0.242 \pm 0.023$ & $0.0194 \pm 0.0027$ \\
\hline 2.4 & 14 & 5 & $0.186 \pm 0.011$ & $0.178 \pm 0.011$ & $0.0132 \pm 0.0015$ \\
\hline 2.4 & 19 & 10 & $0.269 \pm 0.015$ & $0.260 \pm 0.015$ & $0.0199 \pm 0.0023$ \\
\hline 2.4 & 29 & 10 & $0.193 \pm 0.011$ & $0.190 \pm 0.011$ & $0.0147 \pm 0.0016$ \\
\hline 2.4 & 39 & 20 & $0.274 \pm 0.014$ & $0.278 \pm 0.016$ & $0.0179 \pm 0.0020$ \\
\hline 2.4 & 59 & 20 & $0.190 \pm 0.010$ & $0.195 \pm 0.011$ & $0.0117 \pm 0.0013$ \\
\hline 2.4 & 79 & 20 & $0.144 \pm 0.008$ & $0.149 \pm 0.008$ & $0.0091 \pm 0.0011$ \\
\hline 2.4 & 99 & 50 & $0.248 \pm 0.013$ & $0.254 \pm 0.014$ & $0.0125 \pm 0.0015$ \\
\hline 2.4 & 149 & 50 & $0.159 \pm 0.008$ & $0.163 \pm 0.009$ & $0.0084 \pm 0.0010$ \\
\hline 2.4 & 199 & 100 & $0.206 \pm 0.011$ & $0.206 \pm 0.012$ & $0.0117 \pm 0.0013$ \\
\hline 2.4 & 299 & 301 & $0.319 \pm 0.020$ & $0.307 \pm 0.020$ & $0.0195 \pm 0.0024$ \\
\hline 100.4 & 10 & 20 & $0.211 \pm 0.021$ & $0.227 \pm 0.022$ & $0.0112 \pm 0.0016$ \\
\hline 100.4 & 30 & 20 & $0.149 \pm 0.012$ & $0.161 \pm 0.013$ & $0.0075 \pm 0.0010$ \\
\hline 100.4 & 50 & 50 & $0.249 \pm 0.015$ & $0.266 \pm 0.018$ & $0.0112 \pm 0.0013$ \\
\hline 100.4 & 100 & 50 & $0.162 \pm 0.009$ & $0.169 \pm 0.010$ & $0.0073 \pm 0.0008$ \\
\hline 100.4 & 150 & 100 & $0.212 \pm 0.011$ & $0.212 \pm 0.012$ & $0.0093 \pm 0.0010$ \\
\hline 100.4 & 250 & 100 & $0.145 \pm 0.008$ & $0.138 \pm 0.008$ & $0.0078 \pm 0.0009$ \\
\hline 100.4 & 350 & 200 & $0.206 \pm 0.011$ & $0.186 \pm 0.010$ & $0.0105 \pm 0.0011$ \\
\hline 100.4 & 550 & 200 & $0.150 \pm 0.008$ & $0.129 \pm 0.007$ & $0.0077 \pm 0.0009$ \\
\hline 100.4 & 750 & 200 & $0.120 \pm 0.006$ & $0.101 \pm 0.006$ & $0.0061 \pm 0.0007$ \\
\hline 100.4 & 950 & 500 & $0.224 \pm 0.012$ & $0.185 \pm 0.010$ & $0.0109 \pm 0.0012$ \\
\hline 100.4 & 1450 & 500 & $0.161 \pm 0.008$ & $0.132 \pm 0.007$ & $0.0081 \pm 0.0009$ \\
\hline 100.4 & 1950 & 500 & $0.123 \pm 0.006$ & $0.100 \pm 0.006$ & $0.0061 \pm 0.0007$ \\
\hline 100.4 & 2450 & 11950 & $0.757 \pm 0.046$ & $0.636 \pm 0.041$ & $0.0373 \pm 0.0044$ \\
\hline
\end{tabular}

(a) Time interval between the end of the irradiation and the beginning of the counting interval. 


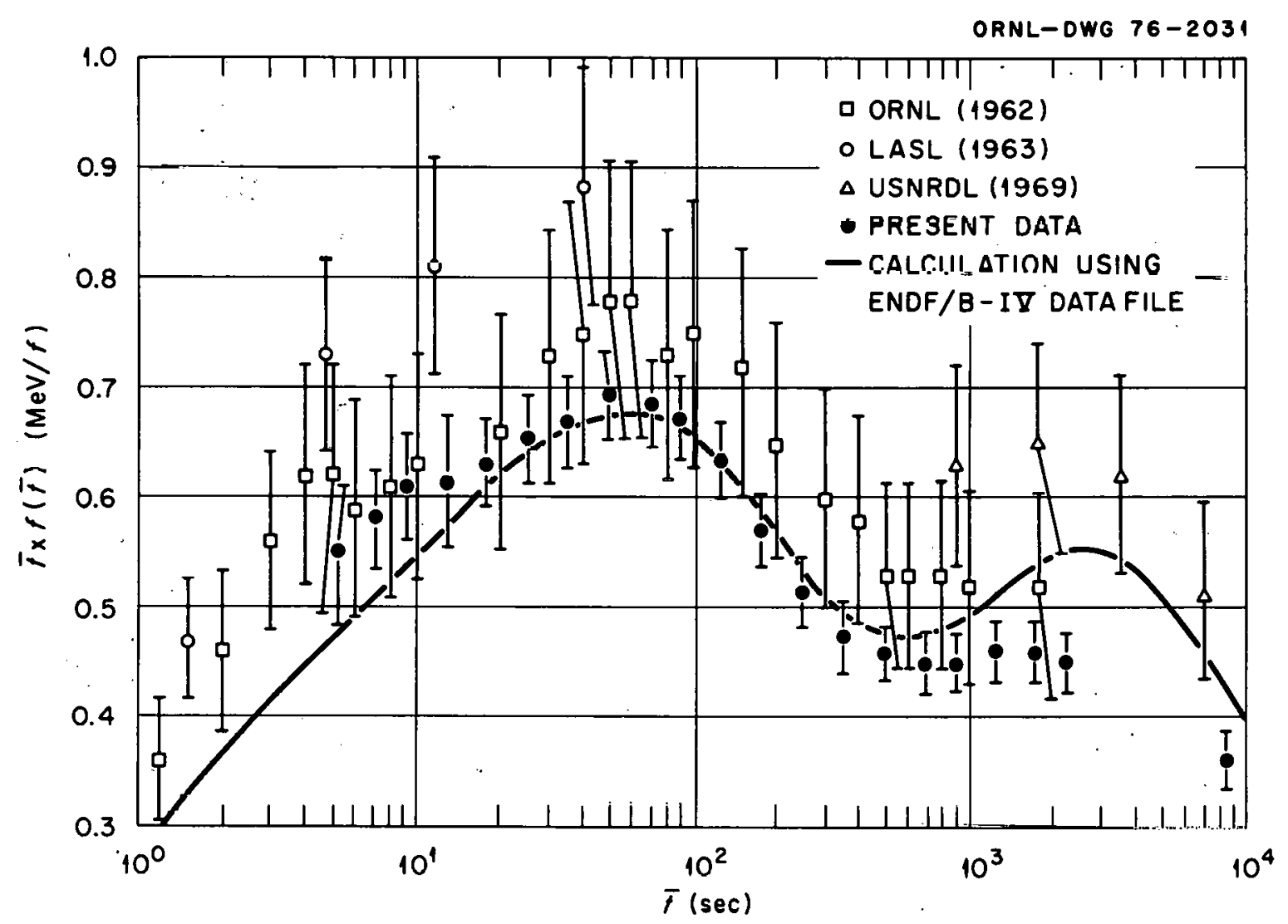

Fig. 2. Photon energy emission rate for thermal-neutron fission of ${ }^{23}{ }^{5} \mathrm{U}$. The open squares are the data of Peelle, et al., (Ref. 25), open circles represent data of Fisher and Engle (Ref. 26 ), and the open triangles are data of Bunney and Sam (Ref. 27). The calculation was carried out by R. Schenter (Hanford) using the RIBD code (Ref. 3) and the ENDF/B-IV data file. ${ }^{31}$ 
results to account for the finite irradiation and counting times. Most of these were < $3 \%$; however, the entry for $t \sim 9 \times 10^{3}$ sec required $\sim 20 \%$ reduction to approximate $\underline{t} \times f(\underline{t})$ because of the long counting-time interval.) The present interim results are definitely lower than all prior measurements for $\underline{t}>10 \mathrm{sec}$. One important unexpected result is the discrepancy between the present interim data and the calculation for $t$ $>10^{3} \mathrm{sec}$.

As mentioned in the Introduction, differential gamma-ray spectra can be calculated from known fission product data. Such calculations have been carried out using the ORIGEN $\operatorname{code}^{5}$ for comparison with the present intèrim data; several of these are presented in Figs. $3-14$. As expected the data are larger than calculation for short waiting times because much of the decay energy for shorter-iived nuclides is given in the ENDF/B file upon which the calculation was based as average energy release. The calculations do a better job of reproducing the data for longer $t$. It is interesting, though, that even with the relatively poor resolution of the present data, study of the comparisons presented in Fiys. 3 - 14 should be very helpful in improving the basic data file.

\section{INTERIM BETA-RAY ENERGY RFLEASE RESULTS}

The yield and energy-release per fission results are collected in Table 2. These data include estimates for beta rays not observed for $E_{\beta}$ $<0.25 \mathrm{MeV}$. For the energy-release data, these estimates ranged from $<1 \%$ for shortest cooling times to $12 \%$ for the last entry in the table. For the yield data these estimates ranged from 5 to $15 \%$, with increased uncertainties for the last six entries. The overall uncertainties are 


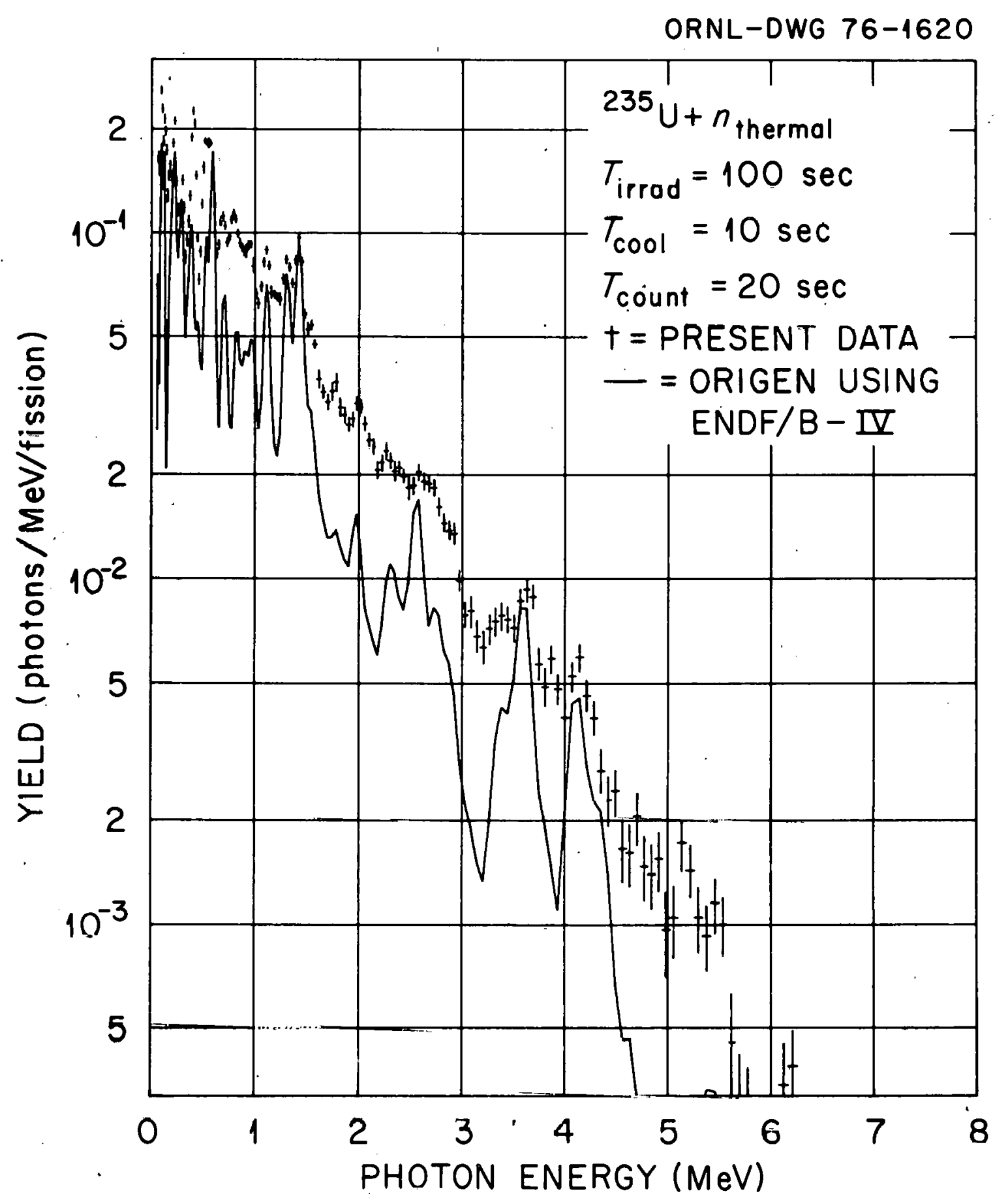

Fig. 3. Comparison of present gamma-ray spectra (crosses) from thermal-neutron fission of ${ }^{235} \mathrm{U}$ with calculated spectra (solid line) using ORIGEN. The irradiation time was $100 \mathrm{sec}$. The cooling time and counting interval is given in the legend. 


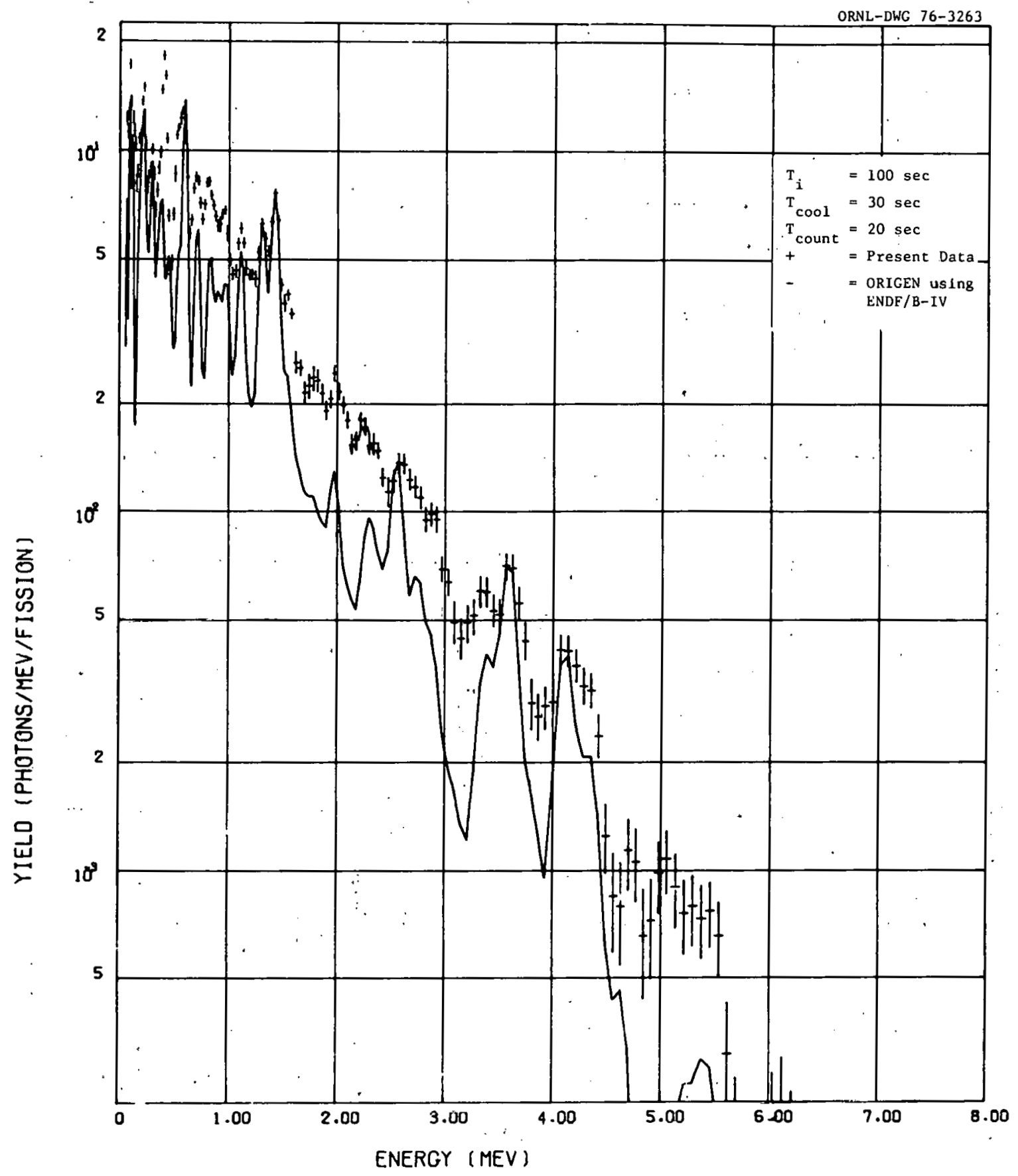

Fi.g. 4 Comparison of present gamma-ray spectra (crosses) from thermal-neutron fission of ${ }^{235} \mathrm{U}$ with calculated spectra (solid line) using ORIGEN. The irradiation time was $100 \mathrm{sec}$. The cooling time and counting interval is given in the legend. 


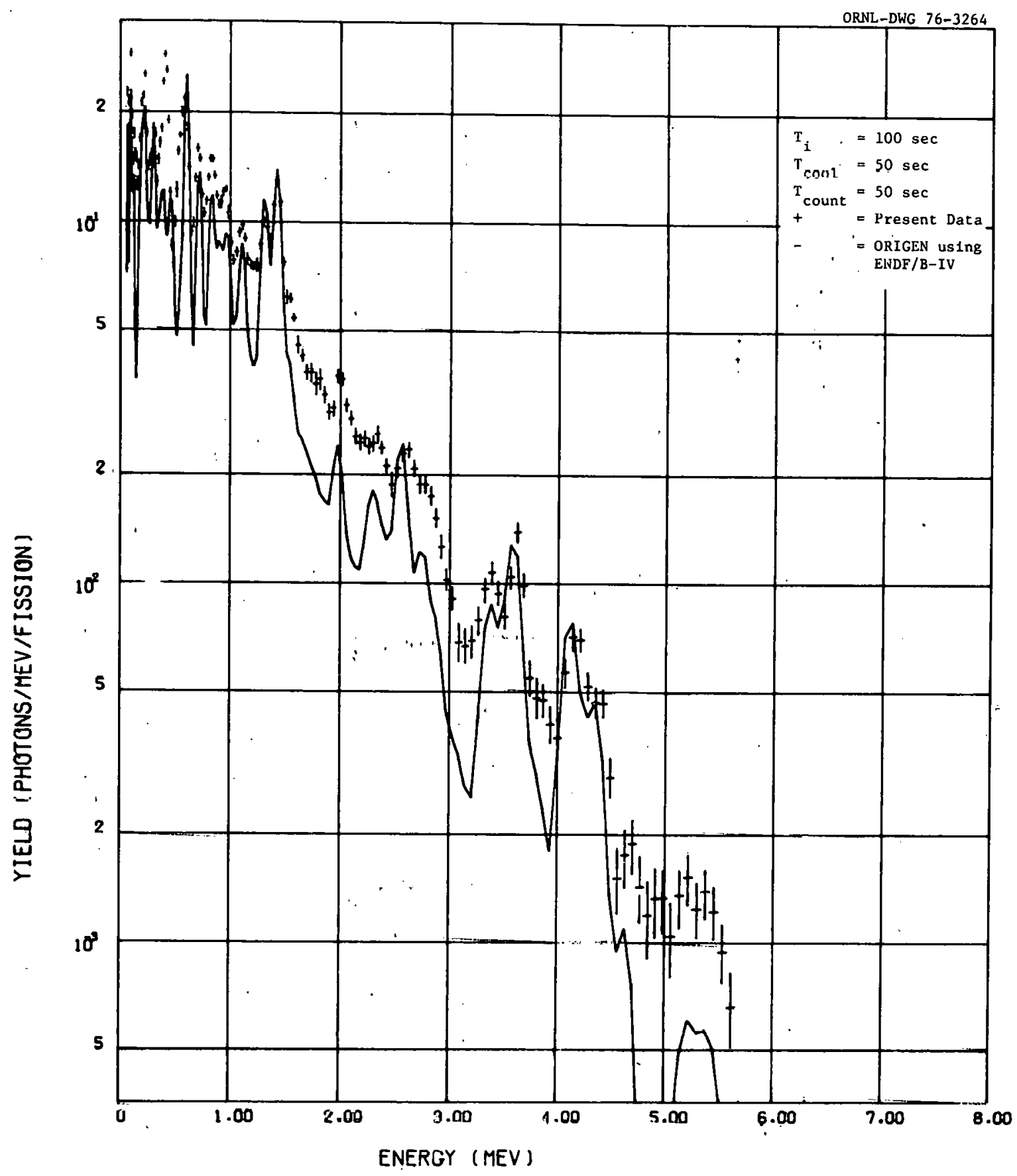

Fig. 5. Comparison of present gamma-ray spectra (crosses) from thermal-neutron fission of ${ }^{235} \mathrm{U}$ with calculated spectra (solid line) using ORIGEN. The irradiation time was $100 \mathrm{sec}$. The cooling time and counting interval is given in the legend. 


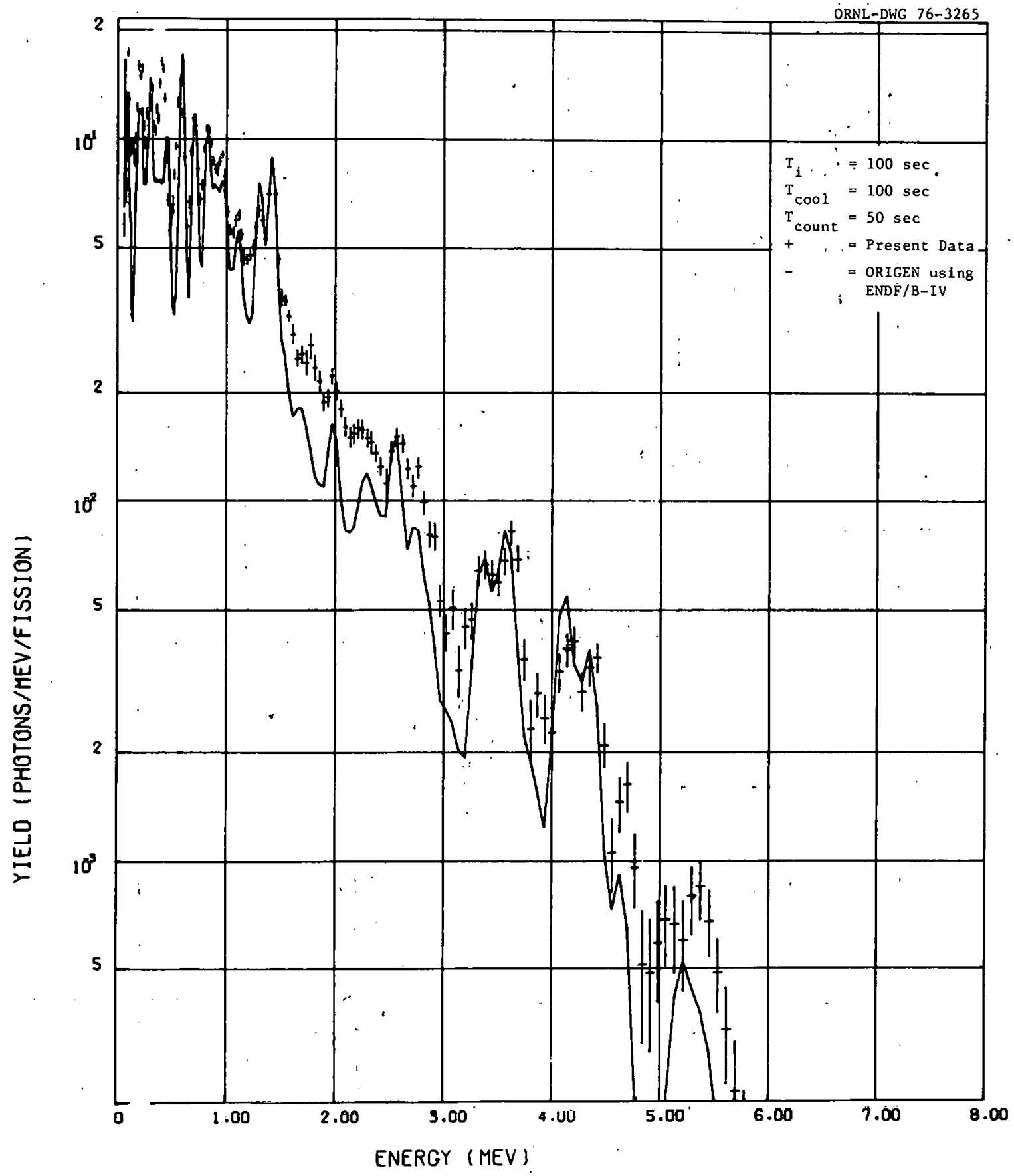

Fig. 6. Comparison of present gamma-ray spectra (croșses) from thermal-neutron fission of ${ }^{235} \mathrm{U}$ with calculated spectra (solid line) using ORIGEN. The irradiation time was $100 \mathrm{sec}$. The cooling time and counting interval is given in the legend. 


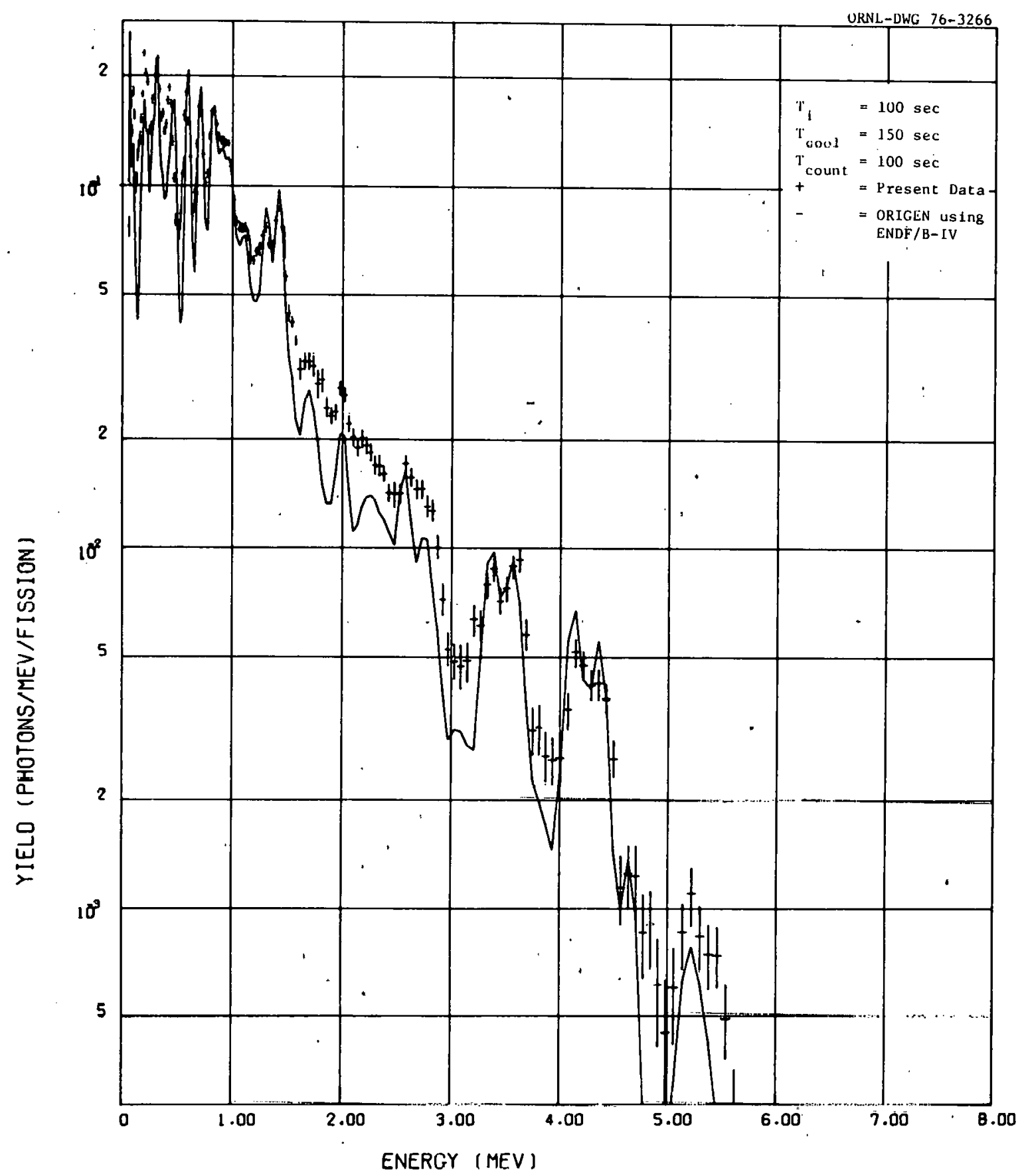

Fig. 7. Comparison of present gamma-ray spectra (crosses) from thermal-neutron fission of $235 \mathrm{U}$ with calculated spectra (solid line) using ORIGEN. The irradiation time was $100 \mathrm{sec}$. The cooling time and counting interval is given in the legend. 


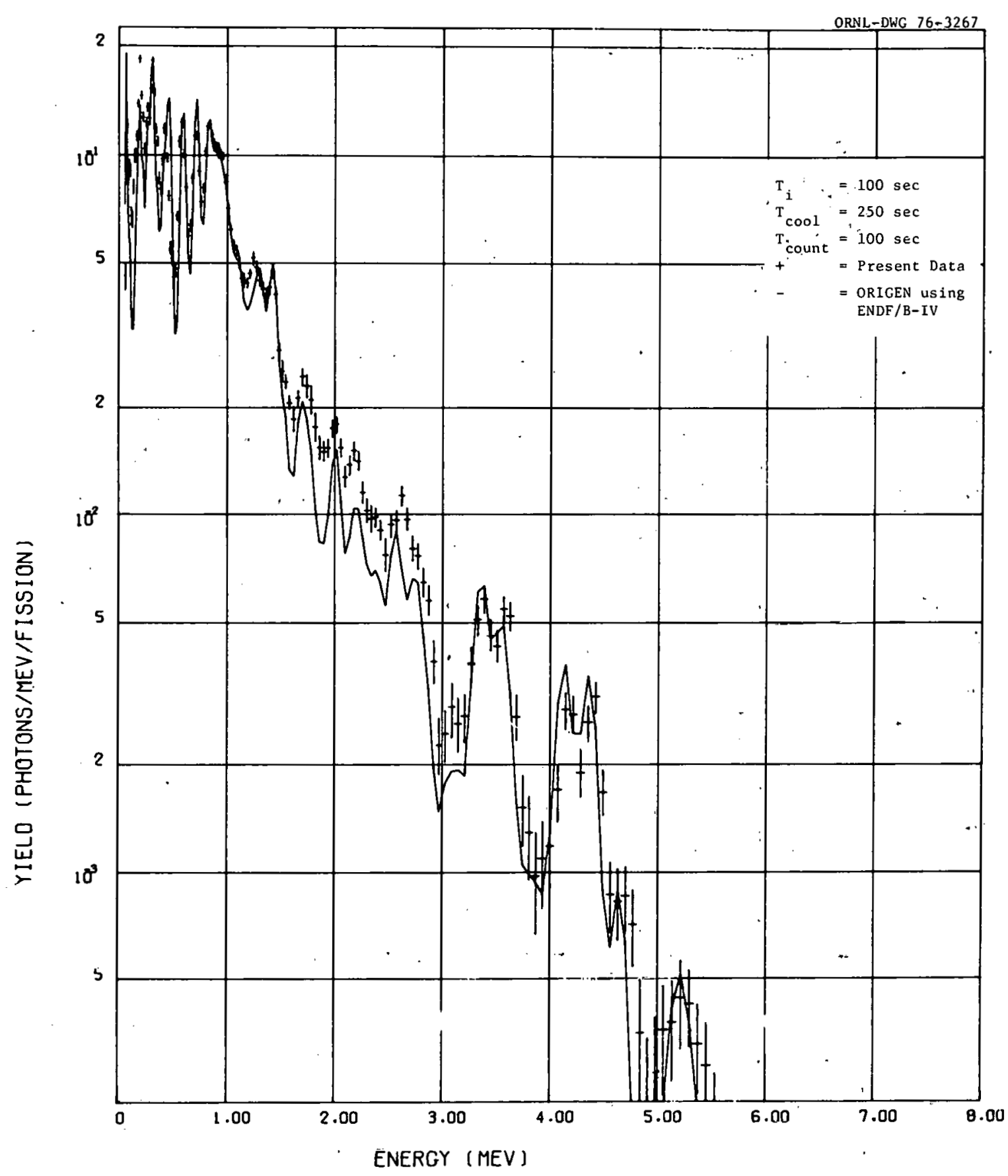

Fi.g. 8. Comparizon of present gamma-ray spectra (crosses) from thermal-neutron fission of ${ }^{235} \mathrm{U}$ with calculated spectra (solid line) using ORIGEN. The irradiation time was 100.sec. The cooling time and counting interval is given in the legend. 


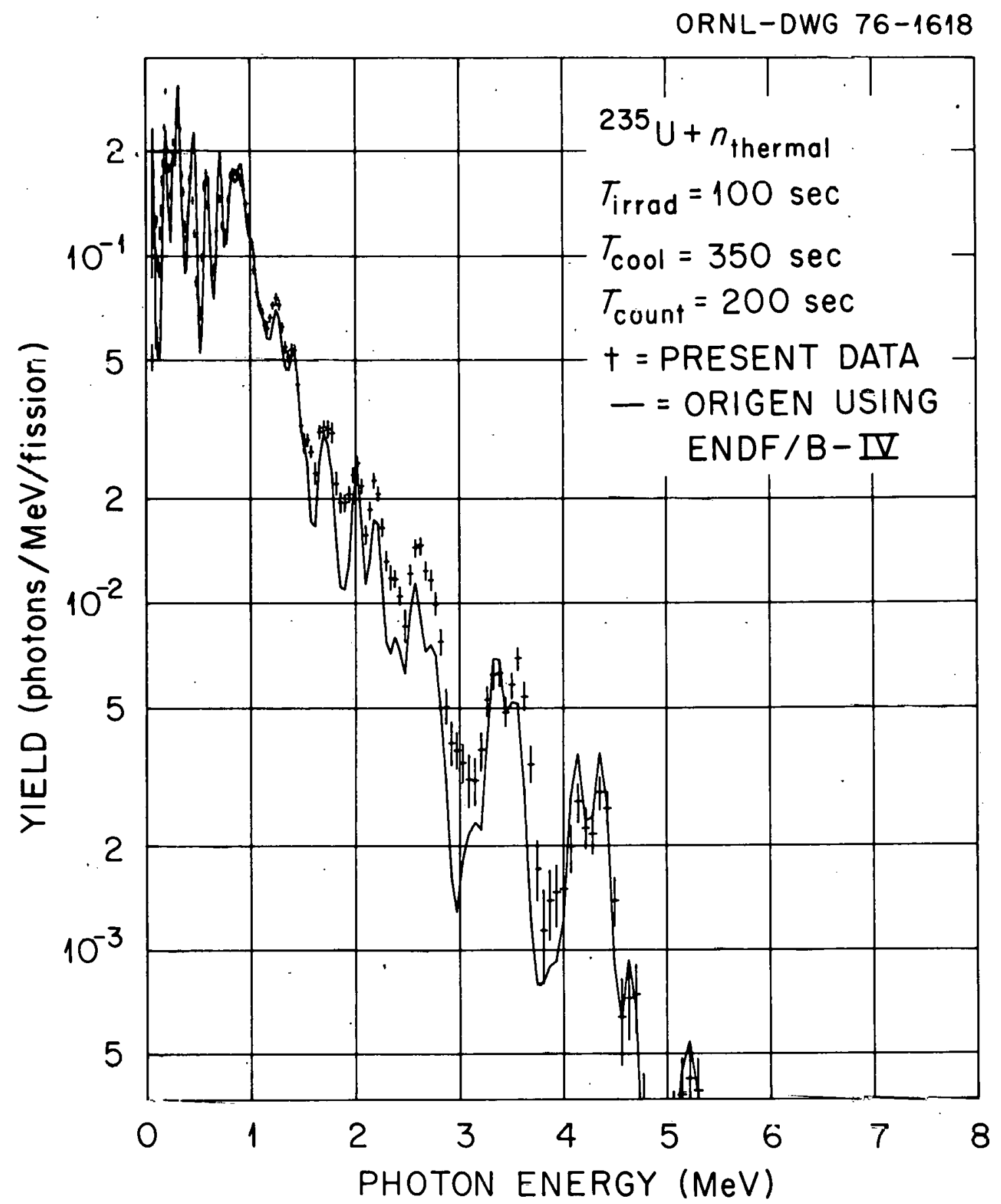

F1g. 9. Comparison of present gamma-ray spectra (crosses) from thermal-neutron fission of ${ }^{235} \mathrm{U}$ with calculated spectra (solid line) using ORIGEN. The irradiation time was $100 \mathrm{sec}$. The cooling time and counting interval is given in the legend. 


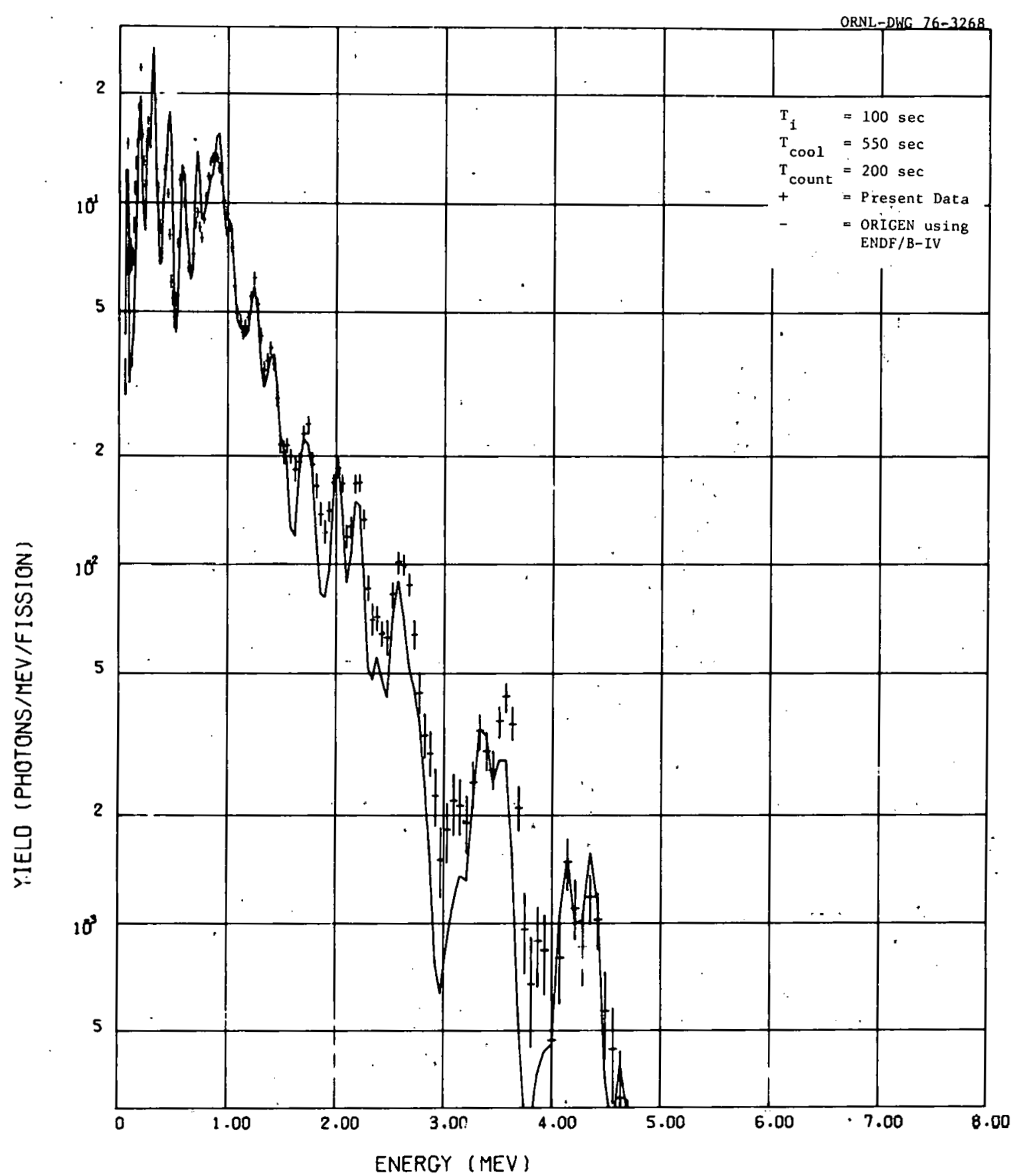

F1g. 10. Comparison of present gamma-ray spectra (crosses). from thermal-neutron fission of ${ }^{235} \mathrm{U}$ with calculated spectra (solid line) using ORIGEN. The irradiation time was $100 \mathrm{sec}$. The cooling time and counting interval is given in the legend.. 


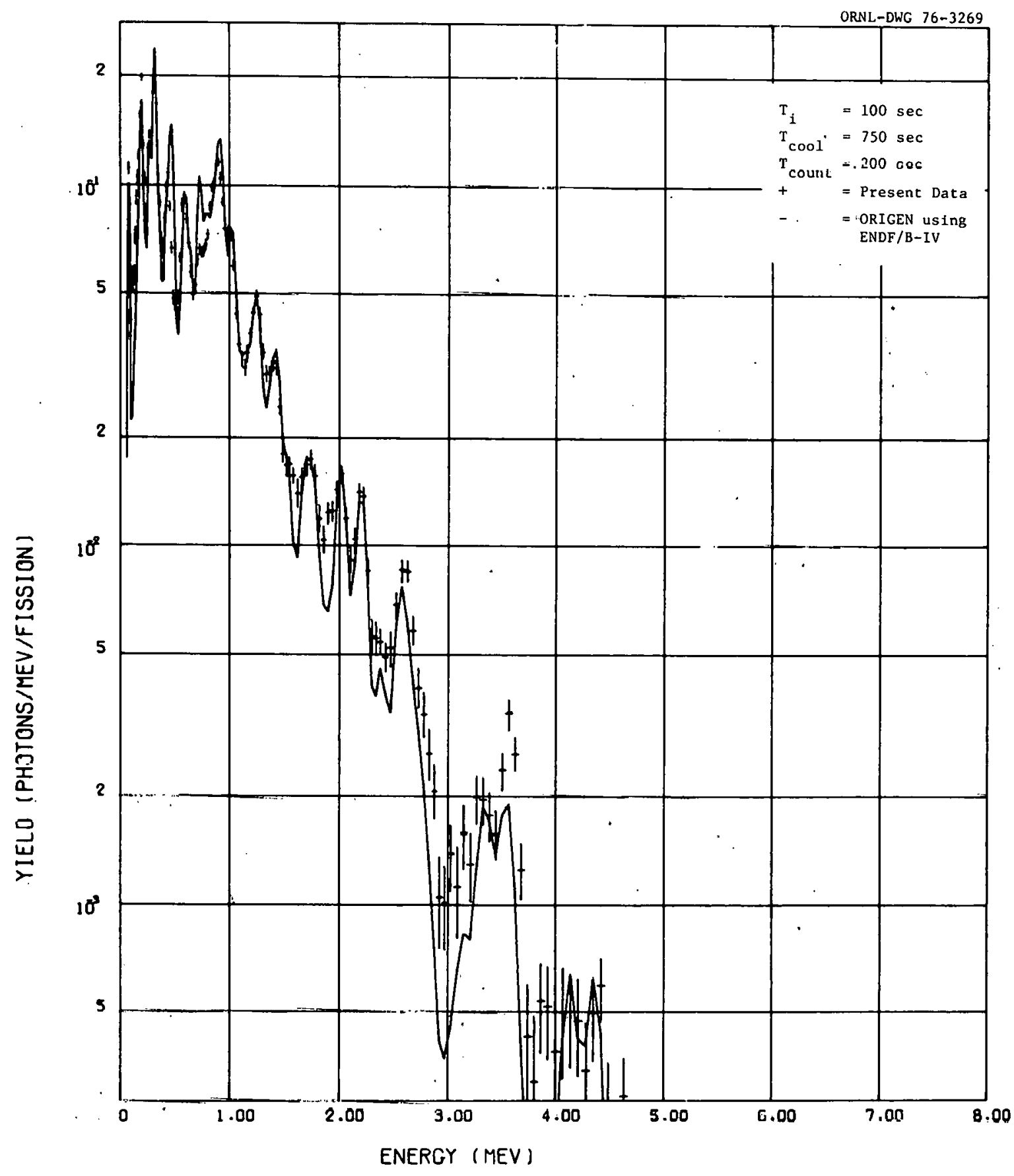

Fig. 11. Comparison of present gamma-ray spectra (crosses) from thermal-neutron fission of ${ }^{235} \mathrm{~W}$ with calculated spectra (solid line) using ORIGEN. The irradiation time was 100 sec. The cooling time and counting interval is given in the legend. 


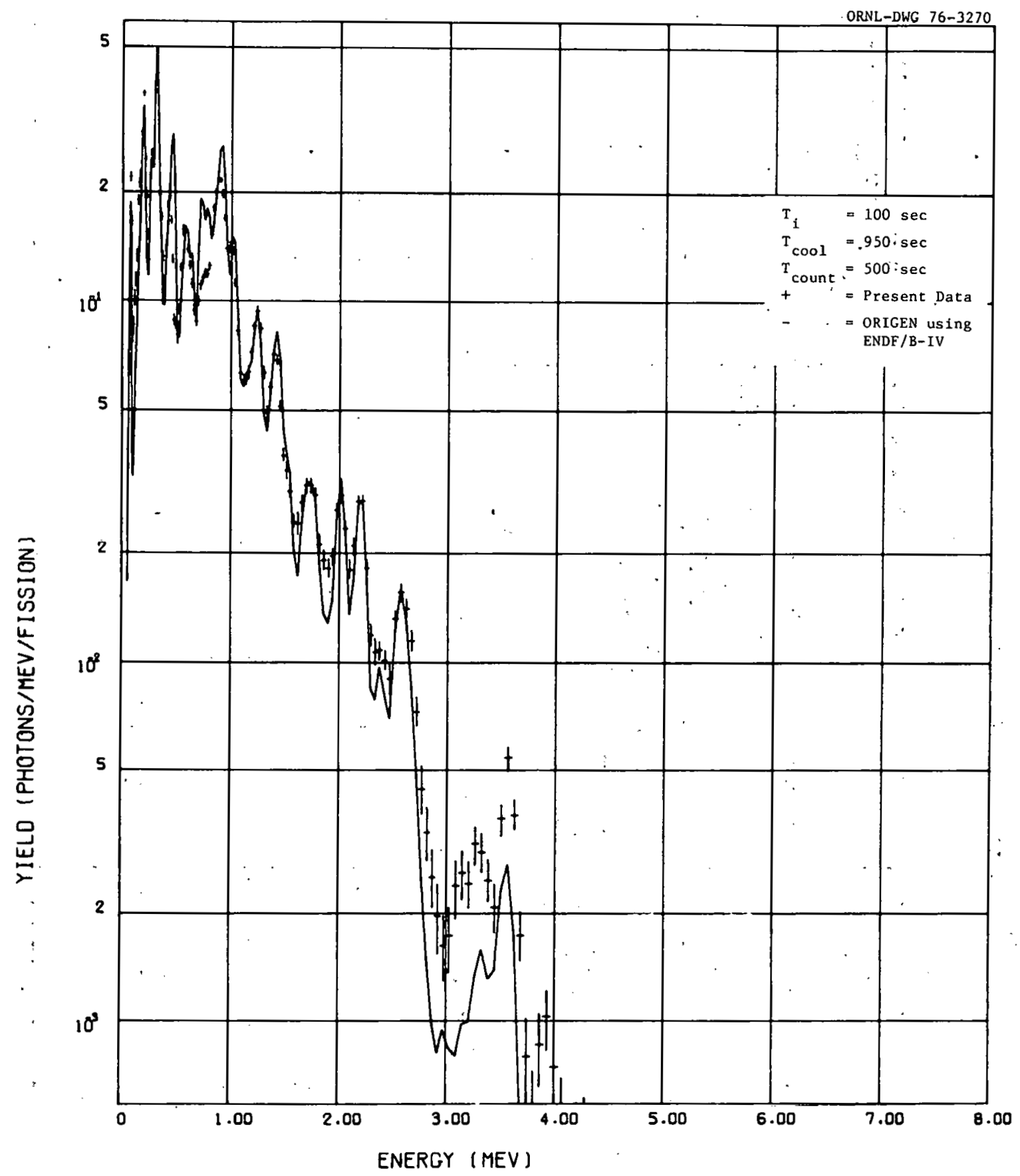

Fig. 12. Comparison of present gamma-ray spectra (crosses) from thermal-neutron fission of ${ }^{235} \mathrm{U}$ with calculated spectra (solid line) using ORIGEN. The Irradiation time was $100 \mathrm{sec}$. The cooling time and counting interval is given in the legend. 


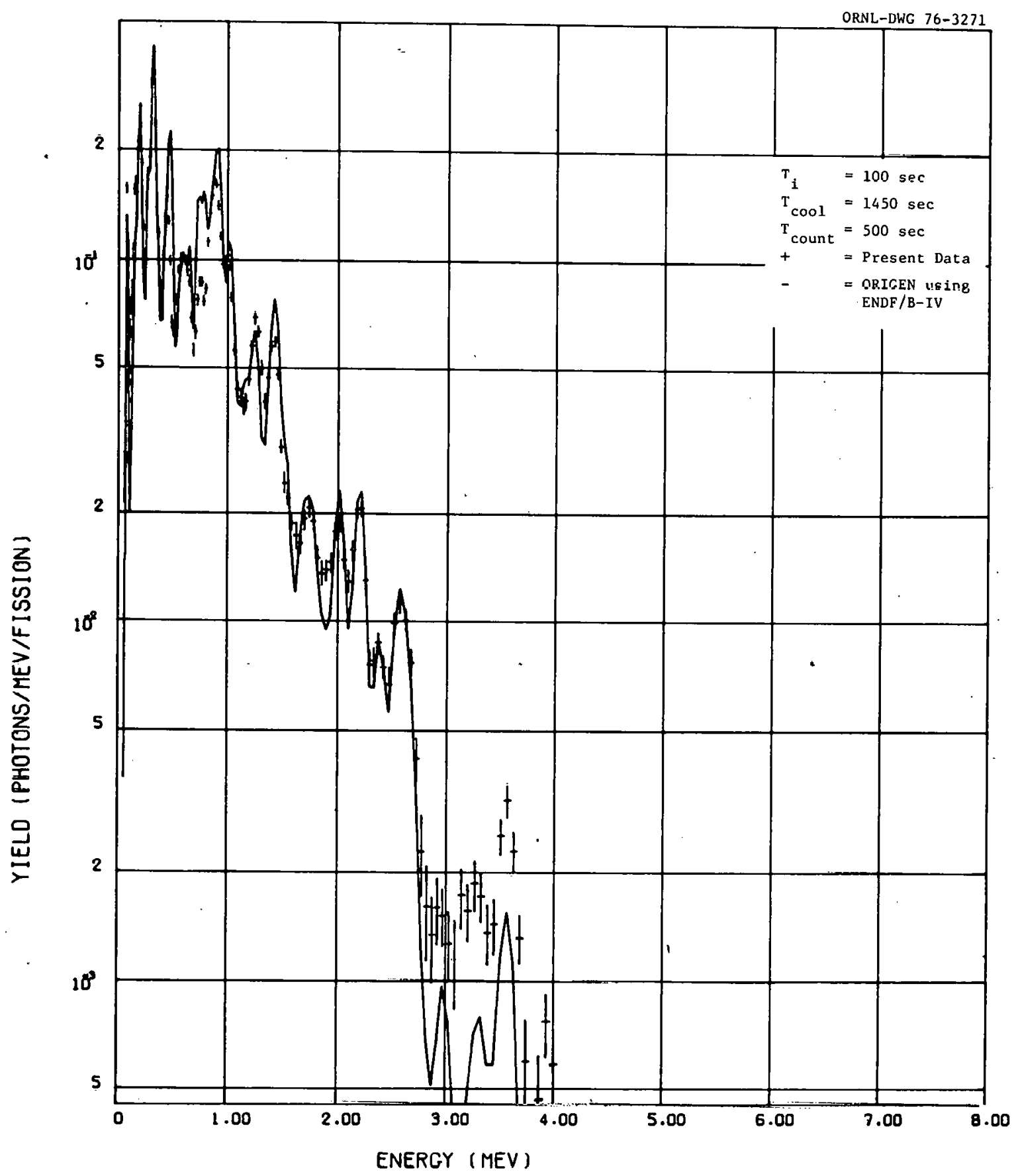

Fig. 13. Comparison of present gamma-ray spectra (crosses) from thermal-neutron fission of ${ }^{235} \mathrm{U}$ with calculated spectra (solid line) using ORIGEN. The irradiation time was $100 \mathrm{sec}$. The cooling time and counting interval is given in the legend. 


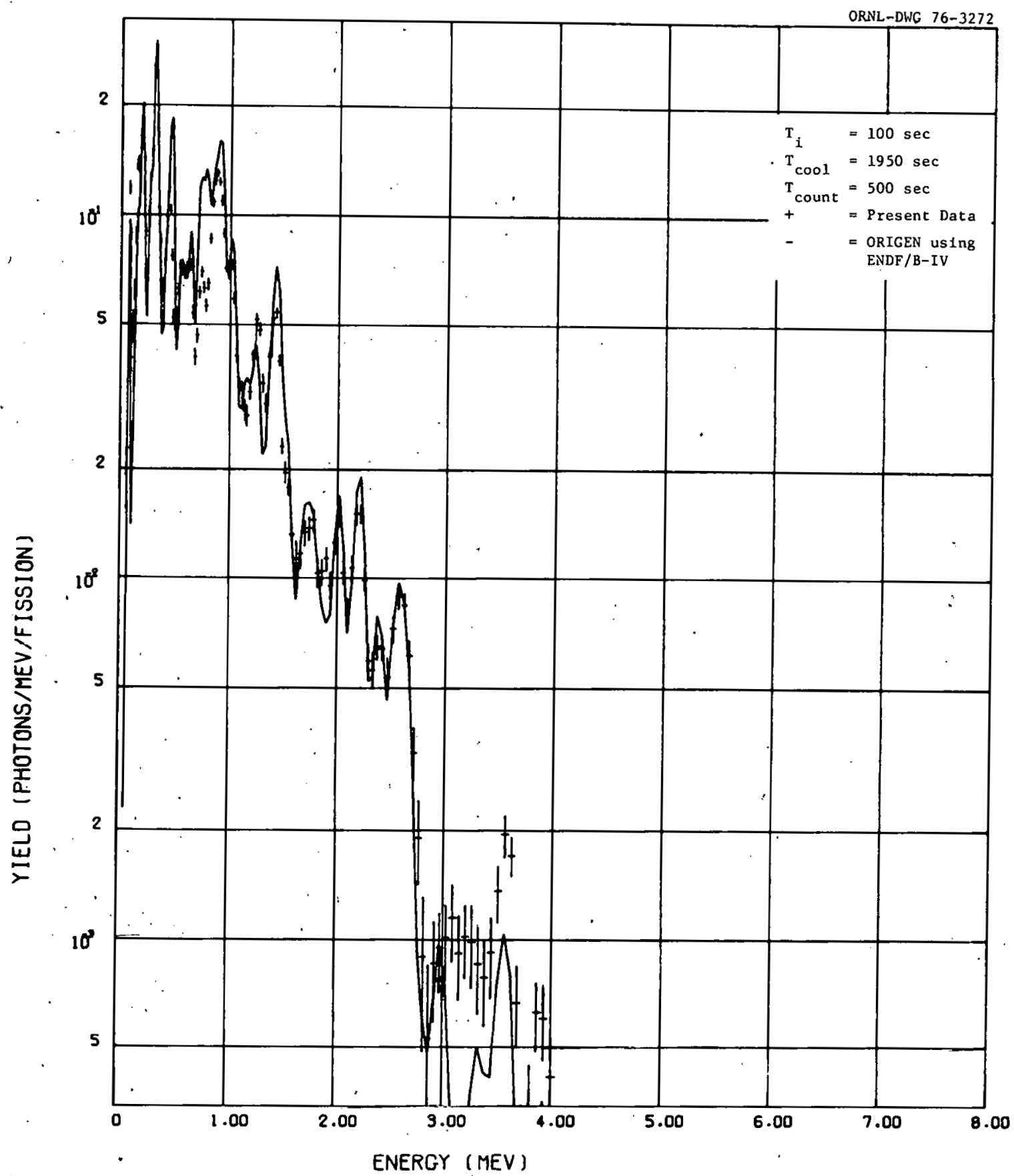

Fig. 14. Comparison of present gamma-ray spectra (crosses) from thermal-neutron fission of ${ }^{235} \mathrm{U}$ with calculated spectra (solid line) using ORIGEN. The irradiation time was $100 \mathrm{sec}$. The cooling time and counting interval is given in the legend. 
Table 2. Beta Yields and Energy Release From Fission Created by Thermal-Neutron Fission of ${ }^{235} \mathrm{U}$ (Preliminary)

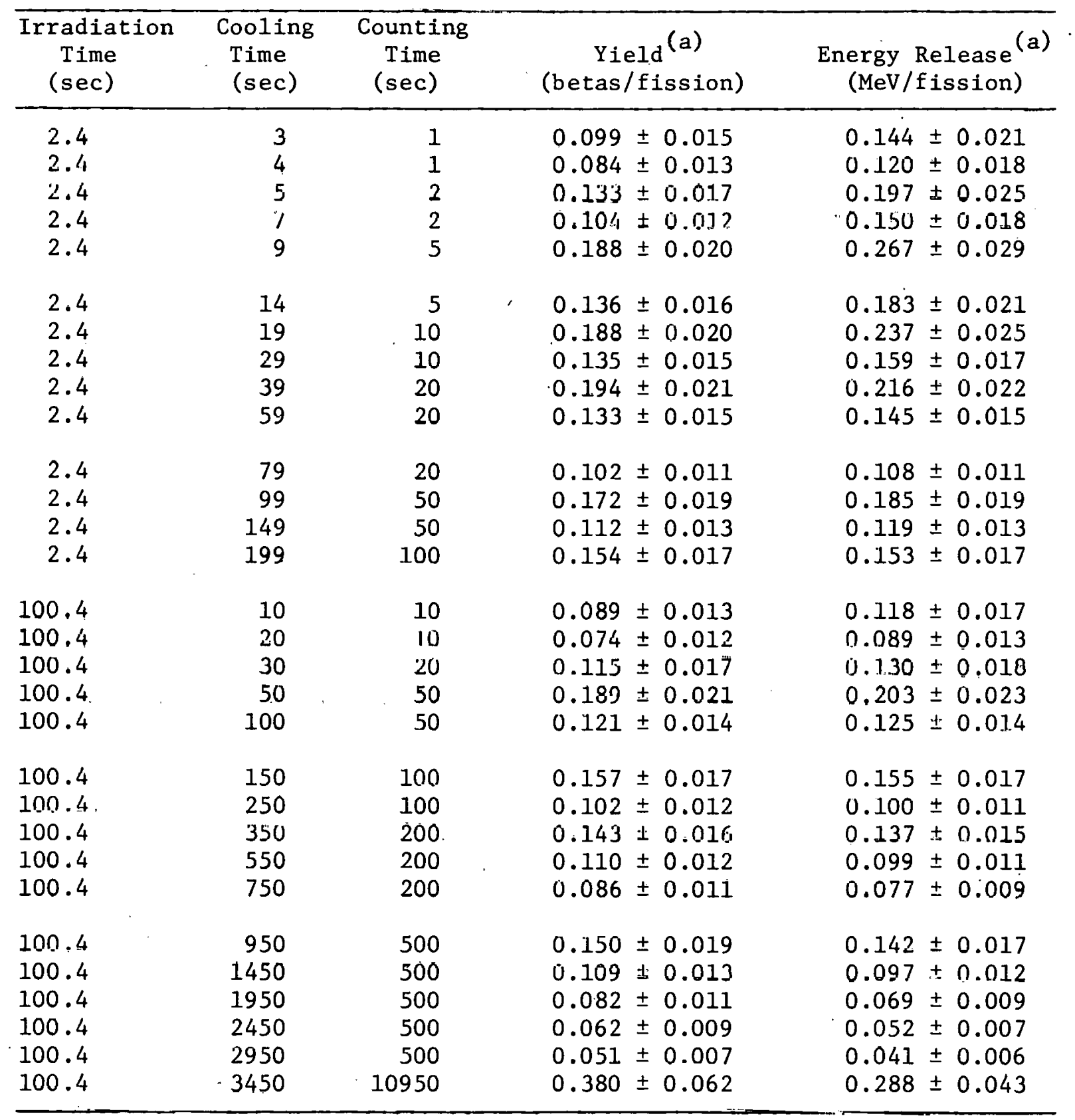

(a) Including estimates for $\mathrm{E}_{\beta}<0.25 \mathrm{MeV}$. 
larger than for the gamma-ray data primarily because the beta-ray raw data were less consistent. However, the larger uncertainties associated with the beta-ray response matrix as well as uncertainties in estimates for $\mathrm{E}_{\beta}<0.25 \mathrm{MeV}$ also contribute to the larger errors.

Comparison with prior results ${ }^{28-30}$ and calculation for the function $\underline{t} \times \mathrm{f}(\underline{t})$ is shown in Fig. 15. (Small corrections for finite irradiation and counting times, as mentioned above for Fig. 2, were similarly applied to the present beta-ray results shown in Fig. 15.) The present interim results are in good agreement with two earlier measurements, ${ }^{28,29}$ but disagree with the latest published results of Tsoulfanidis, et al. ${ }^{30}$ of real cuncern is the lack of agreement with the calculation using the ENDF/B-IV data file. The file is being improved ${ }^{31}$ in preparation for release as ENDF/B-V.

At present, differential beta-ray spectra (similar to Figs. $3-14$ for the gamma-ray results) cannot be calculated. The primary coding requirement needed is a method of computing the beta-ray spectrum given the parent isotope, $\log (f t)$ value, end-point energy, and intensity. One possiblc assumptiun whlch may be valid for the waiting times $t$ of the present experiment would be to assume that all beta decays observed are allowed. Then using tabulated values of the Fermi functions (of the atomic number) the spectrum for each beta-ray decay can be computed. 


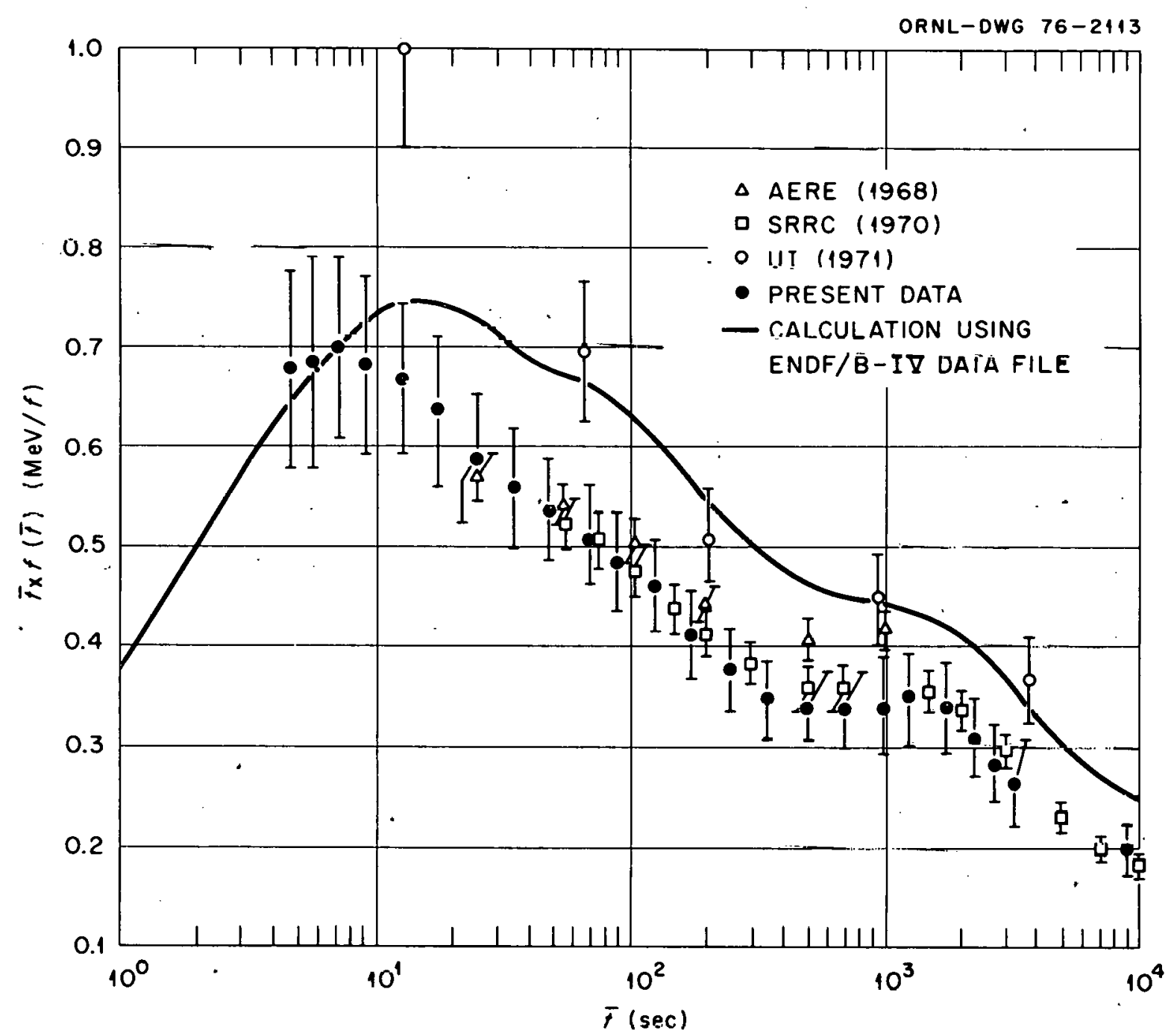

Fig. 15. Beta energy emission rate for thermal-neutron fission of ${ }^{2}{ }^{5} \mathrm{U}$. The open triangles are data of McNair, et al. (Ref. 28), the open squares of MacMaliun, et al. (Ref. 29), and the open circles of I'soulfanid1e, 바 al. (Rcf. 30). The calculation was carried out by R. Schenter (Hanford) using the RIBD code (Ref. 3). 


\section{ACKNOWLEDGMENTS}

We wish to express our appreciation to H. Weaver, J. Northcutt, E. Plemons, G. Morrison, C. Miller, R. Abele, R. Freestone, V. Emert, N. Case, C. McFarland, C. Murin, and R. Seals for their assistance on this project. We also thank D. Vondy, R. Gwin, C. Weisbin, and G. L. Morgan for pertinent discussions, and to F. C. Maienschein for originally suggesting the problem and for support and encouragement. 
Appendix. Brief Resume of Computer Codes

The following eight routines represent the current status of programming for data accumulation through data reduction. The subheadings indicate Function of the Program: NAME (computer).

A. Data Acquisition: ORCONE (PUP-15)

Use a PDP-15 with $24 \mathrm{~K}$ memory. Two parameters of data (a pulseshape-discrimination system is used to provide a "Tag" bit in addition to the pulse-height output from the linear amplifier) are input to the computer a single word having a maximum of 12 meaningful bits. At present 10 are used. Ihe program sorts the data accurding to "Tagged" or "Untagged", with the former including the alpha spectrum used as a gain-shift monitor, and the latter containing the data of interest. Two 512-channel spectra are stored in memory. The initial channel shifts by 1024 locations at the expiration of each predetermined counting time interval. Data for 18 time intervals can be stored in memory. Scaler information is also kept in memory.

At the end of each run, the data are dumped on DECTAPE in standard HUY-15 format. Une DECTAPE holds 6 full-1englh i ins.

B. Transfer of Data from DECTAPE to PDP-10 nisk. Storage: FILEX (PDP-10)

The routine FILEX is a general purpose routine written by DEC, and has the options of reading PDP-15 binary format and writing PDP-10 binary format on disk. Data transfer is effected as soon as practical so that the DECTAPES may be reused. 
C. Transfer of Data from Binary to ASCII: GETT22 (PDP-10)

The program GETT22 prepares an ASCII file from the PDP-10 binary. These long files containing all stored information concerning a run are printed out, and the printed information is scanned for anything suspicious. Information is also obtained which is used to determine dead-time corrections to the data.

D. Addition of Data from Several Equivalent Runs: URANUM and URANM2 (PDP-10)

For each time interval, all of the data--foreground and background--must be corrected for dead time and relative numbers of fissions, and then summed to obtain a single 512-channel pulseheight spectrum and assoclated statistical uncertainties. Gain shifts of $<1 \%$ are not corrected for. If some spectra need to be gain shifted, the code URANM2 has this option at a sacrifice in running time.

E. Binning Pulse-Height Data: ANLYZ (PDP-10)

For each time interval and gain setting, this routine accepts Energy-vs-Channel calibration points, and for the energy bins (specified for either the gamma-ray or the beta-ray unfolding) prepares a suitable file for unfolding.

F. Combining Binned Data of Different Gains: NATMLX (PDP-10)

In both preliminary experiments data were obtained at two different gain settings, with the "High" gain settings providing data to lower gamma- or beta-ray energies than "Low" gain settings. At this point, this very short routine combines the two binned-pulseheight data sets for each time interval. 
G. Unfolding: FERD (360/91)

The binned data, the Response Matrix for the given detector, and the Window functions, along with appropriate Job Control Card Images, are transferred to the IBM $360 / 91$ computer for unfolding. FERD is an updated version of an unfolding routine originally written by R. Burrus. ${ }^{32}$ Unfulding the 176-energy-bin gamma-ray data requires $\sim 1$ min of $/ 91$ time; fort the beta-ray datn, 220 ses is required to unfold the 90 -energy-bin data. In addition to the unfolded data, the total number and integrated energy values are also computed. The data are returned to the PDP-10 for final processing .

H. Absolute Normalization: HEAT (PDP-10)

This routine reads in the number-of-fissions, the unfolded data, and if available, a comparable theoretical data set obtained from ORIGEN. Output consists of plot files and printed values of the integral data.

There are several other ubility routines which are either required for or otherwise useful for the daca reduction and andlysis but are not in the direct flow of data accumulativi to plotted and printed sutput.

I. Preparation of Response Matrix: RESPON (360/91)

For both gamma rays and beta rays the response matrix is calculated using empirically determined functions for peak-to-total, backscattering, etc. The response matrix need not be square. That for the gamma-ray detector is square, $176 \times 176$, but that for the preliminary beta-ray data is not, being $90 \times 100$. 
J: Preparation of the Window Functions: WINDOW (360/91)

The window functions are Gaussian distributions representing the "ideal" detector response. Two additional functions are computed which are interpreted by FERD to give the total number and total energy values.

K. Theoretical Data from ENDF/B-IV: ORIGEN (360/91)

Given the input on the experimental configuration (irradiation, waiting, count times) this general purpose code ${ }^{5}$ prepares a file of either (a) integrated energies for either gamma or beta heating, or (b) a file of discrete gamma-ray energies and intensities from the $\sim 180$ isotopes in the file having this type of information. In this case the percentage of total gamma energy which has been prepared is also printed out.

L. Binning the Theoretical Data: VCOMPR (360-91)

'This program sorts out the gamma-ray information from use (b) of ORIGEN, prints out this information (including the isotopic symbol identifier), and bins the yields into energy bins comparable to the data. The output file resembles a data file except for lack of error information.

M. Plot Raw Data: UTILIT (PDP-10)

This routine follows GETT22. Data from one or two files can be read in and plotted on an oscilloscope for detailed study. Using light-pen manipulation these spectra may be added, subtracted, gainshifted, multiplied or divided by a constant, and integrated. This 
routine is used for an initial look at selected portions of the data prior to step D to ensure that either no gain-shifting is required, or if it is, to determine how much.

N. Plot Fermi-Kurie Plots: ALFERM (PDP-10)

This partially completed routine uses the unfolded output for a beta-ray spectrum to calculate the parameters for a Fermi plot. At present only the beta-rays emanating from ${ }^{28} \mathrm{Al}$ can be done, and the plotting package is not yet complete. 


\section{REFERENCES}

1. S. B. Gunst, D. E. Conway, and J. C. Connor, Nucl. Sci. Eng. 56, 241 (1975).

2. A. M. Perry, F. C. Maienschein, and D. R. Vondy, "Fission Product Afterhead - A Review of Experiments Pertinent to the Thermal-Neutron Fission of ${ }^{235} \mathrm{U}, "$ ORNL-TM-4197 (October 1973).

3. D. R. Marr, "A User's Manual for Computer Code RIBD-II, A Fission Product Inventory Code," HEDL-TME-75-26 (January 1975).

4. T. R. England, R. Wilczynski, and N. L. Whittemore, "CINDER-7: An Interim Report for Users," LA-5885-MS (April 1975).

5. M. J. Bell, "ORIGEN - The ORNL Isotope Generation and Depletion Code," ORNL-4628 (May 1973).

6. C. Devillers, B. Nimal, C. Fiche; J. P. Noel, J, Blachot, and R. de Tourreil, "Sensitivity of the Afterheat from. ${ }^{35} \mathrm{U}$ and ${ }^{239} \mathrm{Pu}$.Thermal Fission to Errors in Fission Product Nuclear Data," Nuclear Cross Sections and Technology, ed. R. A. Schrack and C. D. Bowman, NBS Special Publication 425, p. 29 (1975), CONF-750303.

7. A. Tobias, J. Nucl. Energy 27, 725 (1973).

8. C. W. Reich, R. G. Helmer and M. H. Putnam, "Radioactive-Nuclide Decay Data for ENDF/B," USAEC Report ANCR-1157 (August 1974).

9. C. W. Reich and R. G. Helmer, "Radioactive-Nuclide Decay Data in Science and Technology," Nuclear Cross. Sections and Technology, ed. R. A. Schrack and C. D. Bowman, NBS Special Publication 425, p. 29 (1975), CONF-750303.

10. A. Tobias, "An Ordered Table of Gamma Radiation Emitted by Fission Products," RD/B/M-2356 (June 1972).

11. T. R. England and R. E. Schenter, "ENDF/B-IV Fission-Product Files: Summary of Major Nuclide Data," LA-6116-MS (1975).

12. "Nuclear Decay Data For Selected Radionuclides," ed. M. J. Martin, ORNL-5114 (January 1976). 
13. J. Yarnell and P. Bendt. Funded by USNRC.

14. V. Schrock and L. Grossman. Funded by Electric Power Research Institute (EPRI).

15. V. Rogers and L. Friesenhahn. Funded by EPRI.

16. J. K. Dickens, R. W. Peelle, and F. C. Maienschein, "Experiment for Accurate Measurements of Fission Product Energy Release for Short

Times After Thermal-Neutron Fission of ${ }^{235} \mathrm{U}$ and ${ }^{239} \mathrm{Pu}, "$ ORNL-TM-4676 (May 1975).

17. Quarterly Progress Report on Reactor Safety Programs Sponsored by the Division of Reactor Safety Research for July-September 1974, ORNL-TM-4729, vol. I, Pp. 54-57 (1974).

18. Quarterly Progress Report on Reactor Safety Programs Sponsored by the NRC Division of Reactor Safety Research for OctoberDecember 1974, ORNL-TM-4805, vol. I, pp. 81-83 (1975).

19. Quarterly Progress Report on Reactor Safety Programs Sponsored by the NRC Division of Reactor Safety Research for January-March 1975, ORNL-TM-4914, vo1. I, pp. 55-56 (1975).

20. Quarterly Progress Report on Reactor Safety Programs Sponsored by the NRC Division of Reactor Safety Research for April-June 1975, ORNL-TM-5021, vol. I, pp. 62-64 (1975).

21. G. A. Cristy and J. D. Rylander, "Pneumatic Tube System - ORR," private communication (March 1961).

22. J. K. Dickens, T. A. Love, J. W. McConne11, J. F. Emery and R. W. Peelle, "Fission Product Beta and Gamma Energy Release Quarterly Progress Report for July-September 1975," ORNL-TM-51.56 (1975).

23. J. K. Dickens, T. A. Love, J. W. McConnel1, J. F. Emery, and R. W. Peelle, "Fission Product Beta and Gamma Energy Release Quarterly Progress Report for October-December 1975," ORNL-TM-5272, (in press).

24. R. G. Helmer and R. C. Greenwood, Nucl. Technology 25, 258 (1975). 
25. R. W. Peelle, F. C. Maienschein, W. Zobel and T. A. Love, "The Spectra of Gamma Rays Associated with Thermal-Neutron Fission of $235 \mathrm{U}$, " in "Pile Neutron Research in Physics," IAEA, Vienna (1962). The spectra reported in this reference were integrated, and adding estimates for data below the low-energy cutoff, the total integrated values for yield and energy release are tabulated in Ref. 2 .

26. P. C. Fisher and L. B. Engle, Phys. Rev. 134, B796 (1964).

27. L. R. Bunney and D. Sam, Nucl. Sci. Eng. 39, 81 (1970).

28. A. McNair, F. J. Bannister, R. C, G, Keith and H. W. Wilson, J. Nucl. Energy 23, 73 (1969).

29. T. D. MacMahon, R. Wellum, and H. W. Wilson, J. Nucl. Energy 24, 493 (1970).

30. N. Tsoulfanidis, B. W. Wehring and M. E. Wyman, Nucl. Sci. Eng. $\underline{43}$, 42 (1971).

31. R. Schenter (HEDL), private communication (October 1975).

32. W. R. Burrus, "Utilization of a priori Information by Means of Mathematical Programming in the Statistical Interpretation of Measured Distributions," ORNL-3743 (1965). 
THIS PAGE

WAS INTENTIONALLY

LEFT BLANK 
ORNL/TM-5273

NRC- 1 and -3

\section{INTERNAL DISTRIBUTION}

1. L. S. Abbott

2. J. V. Cathcart

3. R. H. Chapman

4. W. B. Cottrell

5. F. L. Culler

6. J. K. Dickens

7. J. F. Emery

8. G. G. Fee

9. H. Goldstein

10. D. 0. Hobson

11. Gunther Hofmann

12. T. A. Love

13. W. S. Lyon

14. F. C. Maienschein

15. A. P. Malinauskas

16. J. W. McConnell

17. G. W. Morrison

18. F. R. Mynatt

19-38. R. W. Peelle

39. H. Postma

40. R. W. Roussin
41. I. Spiewak

42. D. G. Thomas

43. M. L. Tobias

44. D. B. Trauger

45. D. R. Vondy

46. J. R. Weir

47. C. R. Weisbin

48. J. C. White

49. A. Zucker

50. P. F. Fox (consultant)

51. W. W. Havens, Jr. (consultant)

52. A. F. Henry (consultant)

53. R. E. Uhrig (consultant)

54. ORNL Patent office

55-56. Central Research Library

57-58. Laboratory Records Department

59. Laboratory Records (RC)

60. Nuclear Safety Information

Center

61. ORNL Y-12 Technical Library

Document Reference Section

\section{EXTERNAL DISTRIBUTION}

62-69. Director, Division of Reactor Safety Research, NRC, Washington D. C. 20555.

70. Director, Reactor Division, ERDA-ORO.

71. Director, Research and Technical Support Division, ERDA-ORO.

72-74. Los Alamos Scientific Laboratory, P. O. Box 1663, Los Alamos, New Mexico 87544. Attention: T. R. England, Roger Perkins, and John Yarnell.

75-76. Department of Nuclear Engineering, University of California, Berkeley, California 94720. Attention: L. M. Grossman and V. E. Schrock.

77. B. I. Spinrad, Oregon State University, Corvallis, Oregon 97331.

78. R. E. Schenter, Hanford Engineering Development Laboratory, P. 0. Box 1970, Richland, Washington 99352.

79. A. M. Perry, Institute for Energy Analysis, ORAU, Oak Ridge, Tennessee 37830 .

80. M. R. Remley, Atomics International, 8900 Desoto Street, P. 0. Box 309, Canoga Park, California 91305.

81-82. Aerojet Nuclear Company, 550 Second Street, Idaho Falls, Idaho 83401. Attention: R. L. Heath and Y. D. Harker.

83. F. Ränn, Electric Power Research Institute, P. 0. Box 10412, Palo Alto, California 94301.

84. K. Shure, Westinghouse Electric Corporation, Bettis Atomic Power Laboratory, P. 0. Box 79, West Mifflin, Pennsylvania 15122.

85-390. Given distribution as shown in NRC categories 1 and 3 (25 copies - NTIS). 